\title{
AN APPROACH TO OPTIMISE THE SELECTION OF LNG CARRIERS' PROPULSION SYSTEM
}

\author{
C. H. Marques ${ }^{a}$, \\ C. R. P. Belchior ${ }^{b}$, \\ and J. -D. Caprace ${ }^{\mathrm{b}}$ \\ ${ }^{\text {a }}$ Universidade Federal do Rio Grande \\ Escola de Engenharia \\ Avenida Itália, km 8, CP. 474 \\ Rio Grande, RS, Brasil \\ cristoferhood@oceanica.ufrj.br \\ ${ }^{\mathrm{b}}$ Universidade Federal do Rio de Janeiro \\ Departamento de Engenharia Naval e Oceânica \\ Avenida Horácio Macedo, 2030, CP. 68508 \\ Ilha do Fundão, Rio de Janeiro, RJ, Brasil \\ ABSTRACT \\ Marine transport of natural gas, mostly in its liquid phase, is of growing \\ importance in the global energy markets. The fleet of liquefied natural gas \\ carriers is thereby increasing and being upgraded to enhance its \\ performance. Since there is no well-defined procedure about how to \\ perform the selection of the propulsion system considering the peculiarities \\ of this kind of vessel, this work intend to fill this gap. In other words, the \\ present article aims to propose an approach so that one can perform the \\ optimised selection of liquefied natural gas carriers' propulsion system \\ mainly concerning financial aspects. Firstly, some fundamentals about \\ liquefied natural gas and its transport are presented followed by reasons \\ why the traditional steam turbine propulsion plant was abandoned and dual- \\ fuel diesel engines have been applied instead. Then, a list of criteria is \\ discussed and studies that inspired this work are summarised. A case study \\ of a ship with cargo capacity of $174,000 \mathrm{~m}^{3}$ operating between Lake Charles \\ and Tokyo Bay via Panama Canal is selected. Owing to this route and \\ environmental rules, the ship has to travel at three different levels of service \\ speed unlike ordinary ones, which usually keep a steady speed throughout \\ voyage. Maximising the net present value of the project is the objective \\ function that is intended to be achieved by optimising eleven variables \\ regarding synthesis, design and operation of the propulsion system. Finally, \\ Received: May 11, 2017 \\ Revised: June 12, 2017 \\ Accepted: July 06, 2017 \\ it is suggested that this work may assist marine engineers and ship-owners \\ to design and outline the operation of liquefied natural gas carriers. \\ Keywords: propulsion, dual-fuel engine, prime mover, optimisation, LNG
}

\section{NOMENCLATURE}

$1+k_{1}$ form factor of the hull, $\mathrm{N}$

$A_{E} / A_{O}$ blade-area ratio

$C_{\text {form }}$ ship form coefficient

$C_{n} \quad$ coefficients of the Troost series polynomials

$C_{U} \quad$ speed reduction coefficient

$C_{\beta} \quad$ direction reduction coefficient

$D$ propeller diameter, $\mathrm{m}$

$F \quad$ net cash flow, US\$

$i \quad$ discount rate

$J \quad$ advance ratio

$K_{Q} \quad$ non-dimensional torque coefficient

$K_{T} \quad$ non-dimensional thrust coefficients

$n \quad$ number of terms in Troost series polynomials

$n_{e} \quad$ engine speed, rpm

$P / D$ pitch ratio

$P_{B} \quad$ brake power, $\mathrm{W}$

$P_{E} \quad$ effective power, $\mathrm{W}$

$R_{A} \quad$ model-ship correlation resistance, $\mathrm{N}$

$R_{A P P} \quad$ appendage resistance, $\mathrm{N}$

$R_{B} \quad$ additional pressure resistance of bulbous bow near the water surface, $\mathrm{N}$

$R_{F} \quad$ frictional resistance, $\mathrm{N}$

$R_{T} \quad$ total resistance, $\mathrm{N}$

$R_{T R}$ additional pressure resistance due to transom immersion, $\mathrm{N}$

$R_{W} \quad$ wave resistance, $\mathrm{N}$

$s_{n} \quad$ exponents of $J$ (Troost series polynomials)

$t \quad$ total time of project, year

$t_{n} \quad$ exponents of $P / D$ (Troost series polynomials) $u_{n}$ exponents of $A_{E} / A_{O} \quad$ (Troost series polynomials)

$v_{n} \quad$ exponents of $Z$ (Troost series polynomials)

$V_{r w} \quad$ service speed in rough weather, $\mathrm{m} / \mathrm{s}$

$V_{s w} \quad$ service speed in still water, $\mathrm{m} / \mathrm{s}$

$y \quad$ time of cash flow, year

$Z \quad$ blade number of the propeller

$Z_{c} \quad$ number of cylinders

$Z_{p} \quad$ number of propellers and engines

$\eta_{H} \quad$ hull efficiency

$\eta_{O} \quad$ open water propeller efficiency

$\eta_{R} \quad$ relative rotative efficiency

$\eta_{T R M}$ transmission efficiency

\section{Subscripts}

$r \quad$ normalised in relation to nominal maximum continuous rating
Abbreviations
BOG boil-off gas
BOR boil-off rate
CAPEX capital expenditure, US\$
EM engine margin
FP fuel profile
GCU gas combustion unit
HFO heavy fuel oil
ID engine identification
ITTC International Towing Tank Conference 
LNG liquefied natural gas

MDO marine diesel oil

MGO marine gas oil

NMCR nominal maximum continuous rating

NPV net present value, US\$

OPEX operational expenditure, US\$

SFOC specific fuel oil consumption, g/(kW.h)

SGC specific gas consumption, g/(kW.h)

SM service margin

SMCR specified maximum continuous rating

SPOC specific pilot oil consumption, g/(kW.h)

\section{INTRODUCTION}

LNG carriers are specialised ships designed to transport liquefied natural gas (LNG). They are fitted with insulated double-hulled tanks, designed to contain the cargo slightly above atmospheric pressure at a cryogenic temperature without any means of external refrigeration. An average LNG carrier presents tank capacity about $160,000 \mathrm{~m}^{3}$ and typically, the storage tanks operate at $0.3 \mathrm{bar}_{\mathrm{g}}$ with a design pressure of $0.7 \quad \mathrm{bar}_{\mathrm{g}}$ and a cryogenic temperature around $-169^{\circ} \mathrm{C}$. LNG presents typically a density between 430 and $470 \mathrm{~kg} / \mathrm{m}^{3}$, depending on its composition and state. Composition of LNG is predominantly methane $\left(\mathrm{CH}_{4}\right)$ and smaller fractions of ethane $\left(\mathrm{C}_{2} \mathrm{H}_{6}\right)$, propane $\left(\mathrm{C}_{3} \mathrm{H}_{8}\right)$, butane $\left(\mathrm{C}_{4} \mathrm{H}_{10}\right)$ and nitrogen $\left(\mathrm{N}_{2}\right)$ (Mokhatab et al., 2014).

Despite the high degree of insulation, it is impossible to avoid the heat transfer from the surroundings to the cargo; hence some vaporisation will be always present. That evaporated LNG is called boil-off gas (BOG) and its evaporation rate is called boil-off rate (BOR), which is generally about 0.10 to $0.15 \%$ in volume per day, depending on the thermal insulation system (Mokhatab et al., 2014). Vaporisation induces an increase in pressure in the tank, such that a certain amount of the vapour phase should be taken out of the tank to avoid dangerous overpressure. Usually, this outlet gas flow is used as fuel by the propulsion system of the ship to reduce its main fuel consumption (Miana et al., 2010).

For many years steam propulsion plants were practically an exclusive option for LNG carriers due to its capability of burning the unavoidable BOG directly in the power boiler. However, advances in the design of dual-fuel diesel engines, shipboard BOG re-liquefaction plants and marine gas turbines provide meaningful alternatives to the traditional steam power plant. The gas turbine power plants present low weight and volume, flexibility, capability of burning BOG and efficiency higher than steam turbine power plants. On the other hand, its low redundancy, its low efficiency in sea level and its high fuel consumption, as well as the fact of being a relatively untried technology for the commercial ships make it a still unsure option. Hence, diesel engine power plants are currently the most interesting alternative. Propulsion systems based on slow speed two-stroke diesel engines driving fixed pitch propellers with on-board re-liquefaction system have been used successfully in large LNG carriers (Gilmore et al., 2005).

When conventional fuel prices are higher than LNG price, the operational expenditure (OPEX) of propulsion systems that are unable to use BOG as fuel is increased. Moreover, regarding environmental controls, conventional fuels are not as clean as BOG. Thus, an option to overcome these drawbacks is to apply dual-fuel diesel engines. They are compression ignition engines capable to work burning ordinary liquid fuels (diesel mode) or gaseous fuels (gas mode). During diesel mode these engines work as a conventional diesel engine, burning fuels such as marine gas oil (MGO), marine diesel oil (MDO) and heavy fuel oil (HFO). In gas mode though, they burn essentially a gaseous fuel and only a little fraction of liquid pilot fuel is required to start the combustion process (Woodyard, 2009). Thus, it is noticeable that this sort of engine holds three kinds of specific fuel consumption: specific fuel oil consumption (SFOC), specific gas consumption (SGC) and specific pilot oil consumption (SPOC). The former occurs in diesel mode operation whilst the others occur in gas mode.

Since the prime mover is usually operated until the end of the ship's lifetime, its selection is one of the major steps in merchant ship building projects. The importance of each selection criterion differs from one to another ship type, but the factors that influence the selection can be classified overall into two categories: technical aspects, such as noise, vibration, emissions, size, weight and efficiency; and financial aspects, which are summarised by capital expenditures (CAPEX) and OPEX. Although a complete criteria list for choosing main machinery is given by Watson (2002) and many considerations are presented by Lamb (2003), Bulut et al. (2015) defined six major selection criteria. Based on interviews with a group of technical experts and managers of selected shipping companies, the author highlighted: power, acquisition cost, fuel consumption, maintenance, majority in existing merchant fleet and damage history of model.

Power is on the top of the list because the engine needs to be capable to provide enough power to satisfy the ship's operational profile. Acquisition cost is considered one of the major indicators of the financial feasibility of a project because it represents about $10 \%$ of the total cost of a new building project. Another significant indicator of financial feasibility is fuel consumption. Maintenance attributes, in turn, can divide into two considerations: firstly, how easy it can be performed and secondly, how much it costs. Majority in existing merchant fleet, or common practice, is an important aspect once whether a specific model and brand of diesel engine is frequently preferred, this may denote the superiority of that model in overall circumstances. A similar indicator is the damage history of the model, or 
reliability, which illustrates its structural and mechanical hardness in the practical life.

Selecting a suitable propulsion engine model to meet optimally the power demands of a given project dictates attention from the marine engineer. The anticipated load range and the influence that operating conditions are likely to have along the ship's lifetime must be taken into account. Thus, in order to install the necessary propulsion power, the marine engineer needs details about the ship's resistance, as well as the matching propeller-ship, load and the delivered engine power including margins (Woud and Stapersma, 2013). In other words, one needs to obtain the engine's brake power and speed at the specified maximum continuous rating point (SMCR), which is the operational point of maximum power at the maximum speed required in continuous operation of the engine. Therefore, the present paper aims to propose an approach to optimise the selection of LNG carrier propulsion systems concerning financial aspects.

\section{STATE OF THE ART}

Next are summarised the four main papers that inspired the authors for the present work.

Michalski (2007) performed an algorithmic method for determining optimum values of propulsion system parameters in cases where hull resistance and service speed of the ship significantly varies during operation. This work had as objective function to minimise fuel costs by optimising service speed and propeller parameters for a route divided in three parts: deep-water part, shallow-water part and channels.

Dimopoulos and Frangopoulos (2008a) proposed a method for marine energy system optimisation with respect to synthesis of components, their design characteristics and the operation mode during the mission of an LNG carrier fitted with gas turbines, heat recovery steam generators and steam turbines. The objective function in this case was the maximisation of the net present value (NPV) of the investment for three different trading routes.

MAN Diesel \& Turbo (2014) presented a machinery concept comparison of modern LNG carriers to show the most suitable propulsion solution among those supported by itself. Arrangements with conventional slow speed two-stroke diesel engines driving either fixed or controllable pitch propellers with on-board BOG re-liquefaction were compared against arrangements without re-liquefaction plant. CAPEX and OPEX were analysed and the results were compared by using the NPV method. This study was carried out for three different ship capacities and taking into account three price ranges of LNG and HFO.

Lu et al. (2015) conducted a study focused on the development of a ship operational performance prediction model for voyage optimisation towards energy efficient shipping. The model can be used to select the optimum route for minimum fuel consumption taking into consideration average ship speed, encountering sea states and voyage time. In order to predict the added resistance caused by wave and wind, a modified method based on Kwon (2008) was developed.

\section{CASE STUDY}

In order to illustrate the suitability of the methodology, a case study of an actual LNG carrier with cargo capacity of $174,000 \mathrm{~m}^{3}$ operating between Lake Charles and Tokyo Bay via Panama Canal has been proposed. Figure 1 shows the great circle route between the two ports (about 17,117 km) and the applied grid system, as well as the topology of absolute wind speed throughout the region for December 2015. Twenty waypoints were placed on the route and thereby 19 tracks were created.

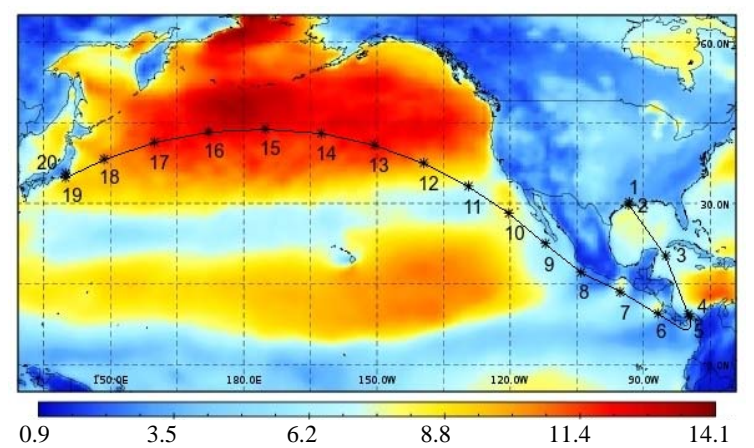

Figure 1. Route between Lake Charles and Tokyo Bay via Panama Canal and the topology of absolute wind speed [m/s] for December 2015.

The ship keeps a different operational profile regarding service speed and fuel to burn depending on the stage of the route. Its maximum service speed must not exceed 12 knots between waypoints 1 and 5 , as well as 19 and 20; 16 knots between waypoints 5 and 11 , as well as 18 and 19; and 19 knots between waypoints 11 and 18. Cleaner fuels, such as MGO and BOG, must be burnt between waypoints 1 and 5, as well as 19 and 20 whilst over the rest of the route either MDO or HFO can be used. Irrespective of fuel profile, additional BOG may be produced by a forcing process whether it is necessary and any surplus may be burnt in a gas combustion unit (GCU). Furthermore, the ship travels in laden from Lake Charles to Tokyo Bay and returns in ballast.

Figure 2 illustrates a scheme of the ship's propulsion plant type wherein electricity is generated separately. Each engine drives a fixed pitch propeller providing propulsion power whilst generators are responsible for keep the electric energy of the shipboard network. There is a BOG compression system that provides it at specified pressure to feed engines and generators. The existence of a re- 
liquefaction plant is not an obligation once BOG can be completely burnt by engines, generators and GCU in a combined manner.

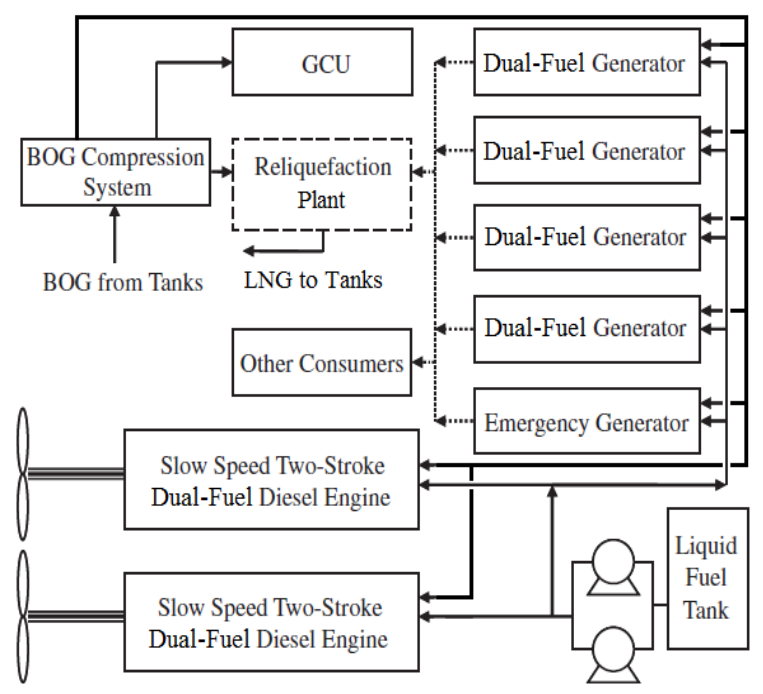

Figure 2. Direct drive propulsion plant scheme (adapted from Chang et al. (2008)).

\section{METHODOLOGY}

The proposed method consists basically in maximising the NPV by following sequentially the twelve steps shown in Fig. 3. However, this flow diagram must be executed iteratively in order to optimise the synthesis of components, their design characteristics and the operational profile. Herein, synthesis of components refers to the condition of the propulsion system to hold one or two main engines, each one driving one propeller, and the existence of shipboard re-liquefaction. The components' design characteristics refer to the propeller geometry and the engine specifications. Finally, the operational profile refers to the service speed and the fuel to be applied for each part of the journey.

\section{Computation of total resistance and propulsion factors in still water}

According to Carlton (2007), many approaches can be used to compute total ship resistance and propulsion factors in still water. The usual approach whenever algebraic models are required is the wellknown Holtrop-Mennen model, defined in Holtrop and Mennen (1982), as well as in Holtrop (1984), which is a statistical power prediction method based on a regression analysis of random model experiments and full-scale test data. Based on geometric parameters and service speed, this model provides an approximated value of total hydrodynamic resistance, as well as mean wake fraction and thrust deduction coefficients, besides relative rotative efficiency. The Holtrop-Mennen model consists briefly in solving the following equation:

$$
R_{T}=R_{F}\left(1+k_{l}\right)+R_{A P P}+R_{W}+R_{B}+R_{T R}+R_{A}
$$

Where $R_{T}$ is total resistance, $R_{F}$ is frictional resistance (according to the ITTC-1957 formula), $1+k_{l}$ is the form factor of the hull, $R_{A P P}$ is appendage resistance, $R_{W}$ is wave resistance, $R_{B}$ is additional pressure resistance of bulbous bow near the water surface, $R_{T R}$ is additional pressure resistance due to transom immersion and $R_{A}$ is the model-ship correlation resistance.

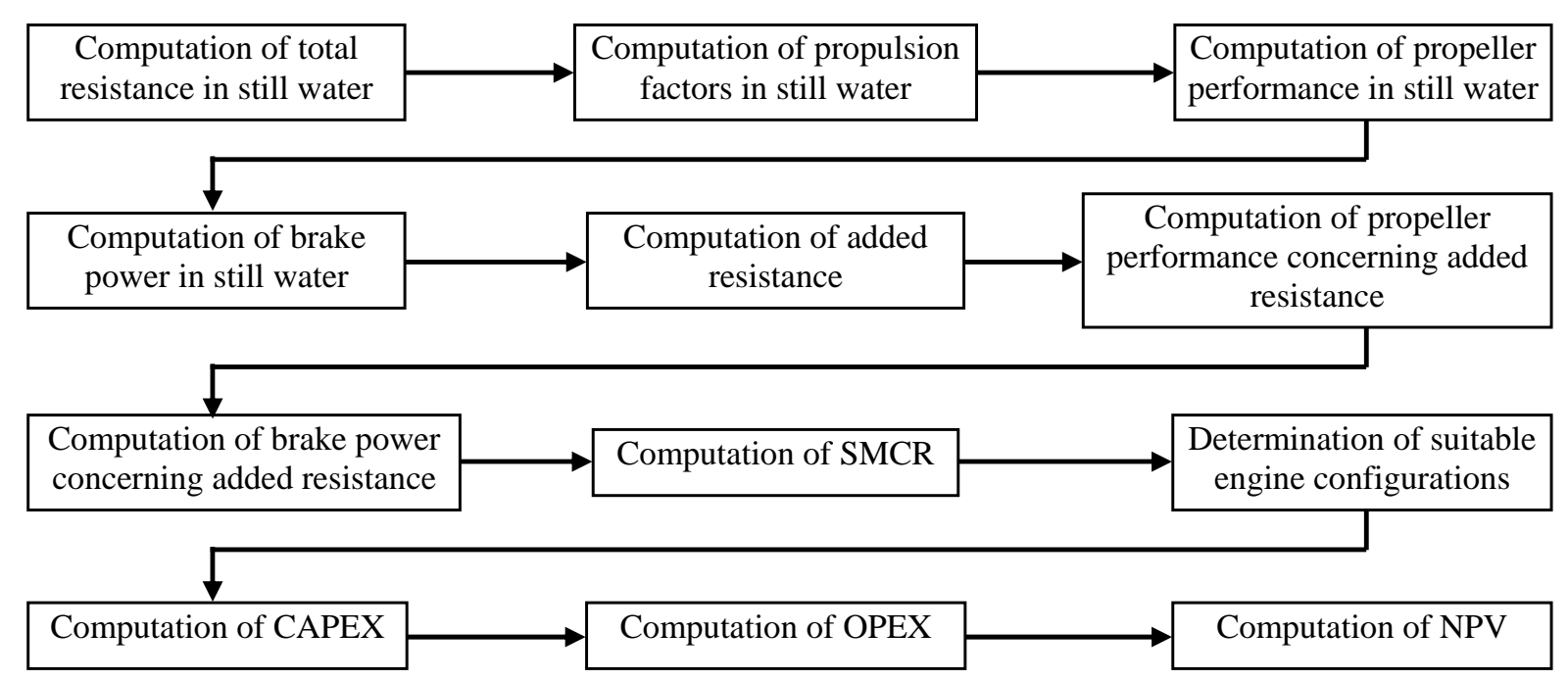

Figure 3. Flow diagram of the proposed optimised selection method. 


\section{Computation of propeller performance}

Over the years there have been a considerable number of standard series propellers tested in many establishments around the world and those most commonly used by propeller designers and analysts are referenced in Carlton (2007). Nevertheless, Wageningen B-screw series, also known as Troost series, is perhaps the most extensive and widely used propeller series as declared by the latter author. Thus, interpolation polynomials deduced from open water tests and published in Oosterveld and Ossannen (1975) may be applied to compute either propeller torque and thrust or Reynolds number effect regarding this series. The non-dimensional torque $\left(K_{Q}\right)$ and thrust $\left(K_{T}\right)$ coefficients, as well as open water propeller efficiency $\left(\eta_{O}\right)$, for Reynolds number value of $2 \cdot 10^{6}$ may be calculated as follows:

$$
\begin{gathered}
K_{Q}=\sum_{n=1}^{47} C_{n}(J)^{s} n(P / D)^{t}{ }^{t}\left(A_{E} / A_{O}\right)^{u} n(Z)^{v_{n}} \\
K_{T}=\sum_{n=1}^{39} C_{n}(J)^{s} n(P / D)^{t} n\left(A_{E} / A_{O}\right)^{u} n(Z)^{v}{ }^{n} \\
\eta_{O}=\frac{1}{2 \pi} \frac{K_{T} J}{K_{Q}}
\end{gathered}
$$

Where $C_{n}, s_{n}, t_{n}, u_{n}$ and $v_{n}$ are constant coefficients, $J$ is the advance ratio, $P / D$ is the pitch ratio, $A_{E} / A_{O}$ is the blade-area ratio and $Z$ is the blade number of the propeller.

\section{Computation of brake power}

Calculating brake power $\left(P_{B}\right)$ is a common procedure for marine engineers (Woud and Stapersma, 2013; Carlton, 2007; Schneekluth and Bertram, 1998) and it is based on the following equation:

$$
P_{B}=\frac{P_{E}}{\eta_{O} \eta_{R} \eta_{H} \eta_{T R M}}
$$

Where $P_{E}$ is effective power, $\eta_{R}$ is relative rotative efficiency, $\eta_{H}$ is hull efficiency (function of wake fraction and thrust deduction coefficients) and $\eta_{T R M}$ is transmission efficiency.

\section{Computation of added resistance}

Owing to the occurrence of rough weather during voyages, the resistance changes and affects the behaviour of the vessel. In order to predict the added resistance, semi-empirical approaches ( $\mathrm{Lu}$ et al., 2015) are more suitable than others more complexes in the present case. The Kwon's model (Kwon, 2008) is an approximate method for predicting speed loss of a displacement ship due to weather conditions (irregular waves and wind). The advantage of this method is that it is easy and practical to use once it is based on the computation of service speed in rough weather $\left(V_{r w}\right)$ through the following equation:

$$
V_{r w}=V_{s w}\left(1-\frac{C_{\beta} C_{U} C_{f o r m}}{100}\right)
$$

Where $V_{s w}$ is service speed in still water (neither wind nor waves), $C_{\beta}$ is a direction reduction coefficient, $C_{U}$ is a speed reduction coefficient and $C_{\text {form }}$ is a ship form coefficient.

In order to calculate these coefficients it is necessary to know some parameters related to weather, such as weather direction angle with respect to the ship's bow and Beaufort Number. The first is assumed to be the same as wind direction (surface waves) whilst the second is a number used to represent a range of wave heights and sea conditions, which can be taken as a function of the wind speed at a height of $10 \mathrm{~m}$ above sea level (Schneekluth and Bertram, 1998). Hence, it is necessary to obtain the wind components at this height over the route so that Kwon's model can be applied.

The dataset from the data server monthly means of daily means provided by the European Centre for Medium-Range Weather Forecasts (http://apps.ecmwf.int/datasets/data/interim-fullmoda/levtype $=\mathrm{sfc} /, 2016$ ) could be used to download data regarding years 2013, 2014 and 2015, for instance. Thus, with aid of geographic information system (Conrad et al., 2015) wind data over the route could be collected and an average wind speed and direction would be calculated.

\section{Computation of SMCR}

Calculating SMCR is also a common procedure for marine engineers (Woud and Stapersma, 2013; Carlton, 2007; Schneekluth and Bertram, 1998) and it is based on the following equation:

$$
S M C R=P_{B} \frac{S M}{E M}
$$

Where $S M$ is service margin and $E M$ is engine margin. The first aims to relate trial condition to service condition whilst the second aims to make the engine to operate below its nominal maximum continuous rating (NMCR) for the majority of the time.

Often the trial condition is the same as the towing tank condition, that is, the ship is clean and usually unloaded, as well as calm seas and deep water are assumed. Accordingly, $S M$ includes effects of fouling, displacement, sea state and water depth. 


\section{Determination of suitable engine configurations}

The first step on engine selection is obtaining the layout diagram of the entire engine programme from most manufacturers and placing the SMCR point on it to know which engines are able to supply the required power and speed. Figure 4 was set up by using data from the Computerised Engine Application System (http://marine.man.eu/twostroke/ceas, 2015) and shows layout diagrams of marine dual-fuel low-speed diesel engines, besides a SMCR of $75 \mathrm{rpm}$ and $50 \mathrm{MW}$. Next step is determining how many cylinders are necessary through detailed information about each engine.

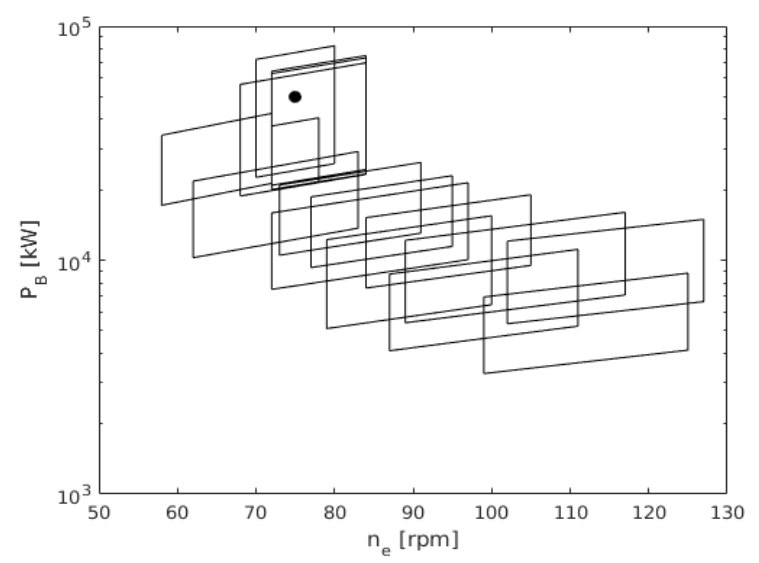

Figure 4. Engine layout diagrams of dual-fuel lowspeed diesel engines.

Depending on the number of cylinders, every engine also owns a layout diagram wherein the ratio of power and speed can be selected. An engine layout diagram is limited by an envelope that defines the area where nominal maximum firing pressure is available for the selection of SMCR. That is to say, it is limited by two lines of constant mean effective pressure, L1-L3 and L2-L4, and by two constant engine speed lines, L1-L2 and L3-L4, wherein L1 refers to the NMCR. Figure 5 illustrates the engine layout diagram of the engine 10S90ME-C9.5-GI and the points SMCR and NMCR.

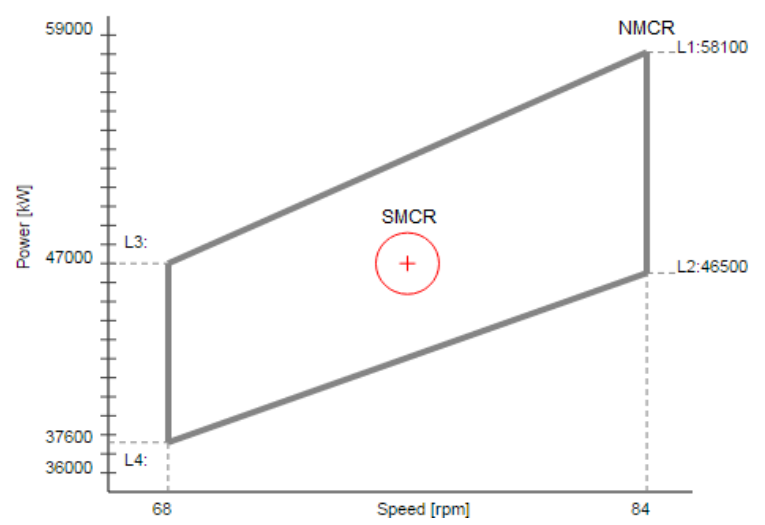

Figure 5. Engine layout diagram of the engine
10S90ME-C9.5-GI (adapted from http://marine.man.eu/two-stroke/ceas, 2015).

\section{Computation of CAPEX}

Among CAPEX, acquisition costs of main engine, propeller, shaft and re-liquefaction plant are of main interest. Nevertheless, obtaining cost and related data is not easy, as engines manufacturers regard this information confidential for their competitors. Hence, Watson (2002) decided to use weight as the estimating parameter once it has the advantage that it applies to almost all components of ship cost. The author reached a curve of weight-related cost that includes materials, labour and overheads, given in US $\$ / t$, versus machinery weight, in tonnes, as shown in Fig. 6. Being the costs given on a 1993 basis, a correction concerning inflation becomes necessary. In this sense, with respect to oil and gas field machinery and equipment manufacturing, the producer price index industry data may be applied (http://data.bls.gov/timeseries/PCU333132333132, 2016).

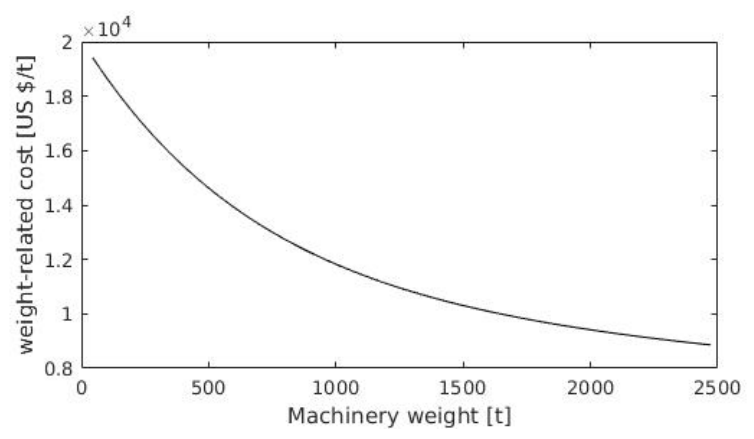

Figure 6. Approximate costs of machinery per tonne.

In order to use this curve it is firstly needed to achieve the mass of each machinery component. Engine mass could be quite easily found in catalogues whilst propeller mass could not because of their practically endless number of configurations. In this sense, the equations provided by Schneekluth and Bertram (1998) could be utilised. These relate mass to basic characteristics of propellers and can be used for normal manganese bronze propellers.

\section{Computation of OPEX}

The most representative measures of OPEX for the present work are fuel costs and BOG reliquefaction costs, in case of on-board re-liquefaction plant, or costs related to loss of LNG cargo due to its evaporation, in case of no re-liquefaction. Computing fuel consumption, knowing fuel unit costs and LNG unit costs is thereby essential to carry out the OPEX estimation. To succeed this assessment, it was developed a particular methodology to estimate specific fuel consumptions whilst the latter ones may 
be taken respectively from websites as Bunker Index (http://www.bunkerindex.com/, 2016) and Energy Information Administration (https://www.eia.gov/, 2016).

A simple polynomial approach was firstly applied to estimate the specific fuel consumptions on the SMCR point and then the specific fuel consumptions for the engine operating in part load. The first is dependent on the position of the SMCR point in the engine layout diagram, that is, it is a function of mean effective pressure and engine speed whilst the second, considering the propeller law (Woud and Stapersma, 2013), is a function of brake power. Thus, by normalising mean effective pressure, engine speed and specific fuel consumptions in relation to the NMCR for a series of engines, surfaces as the one illustrated in Fig. 7 were performed regarding $\mathrm{SFOC}_{\mathrm{r}}, \mathrm{SGC}_{\mathrm{r}}$ and $\mathrm{SPOC}_{\mathrm{r}}$.

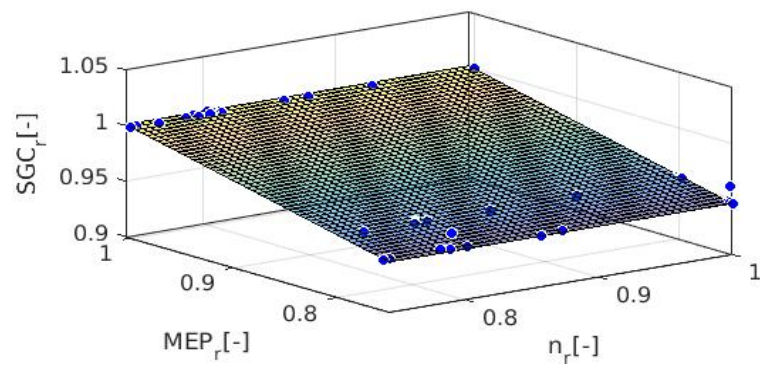

Figure 7. Fitted surface of relative specific gas consumption on the SMCR point.

Likewise, by a normalisation related to the SMCR for the same series of engines, curves as the one illustrated in Fig. 8 were performed as well. By using this approach, it is possible to approximate the specific fuel consumptions for every engine, irrespective of the SMCR position, only by knowing its specific fuel consumption in the NMCR point.

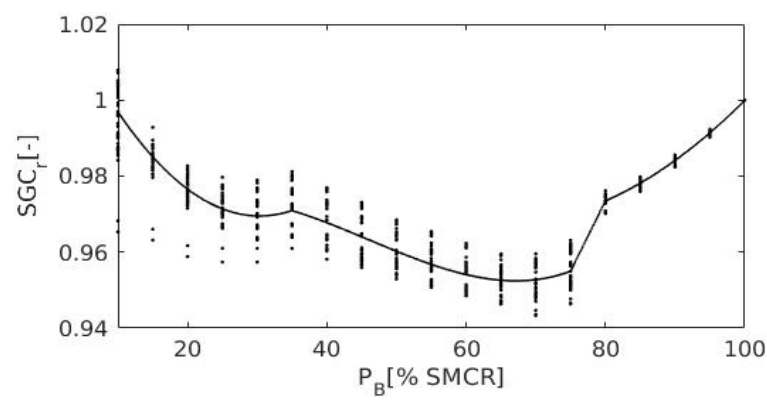

Figure 8. Fitted curve of relative specific gas consumption.

In addition to the aforementioned, it is also indispensable to estimate the BOR to compute either BOG re-liquefaction costs or costs related to loss of LNG cargo due to its evaporation. Although there are quite detailed dynamic BOG models, as the one developed by Dimopoulos and Frangopoulos (2008b), a simpler one is to consider constant BOR
(MAN Diesel \& Turbo, 2014).

\section{Computation of NPV}

In this calculation each cash inflow/outflow is discounted back to its present value and summed afterwards. In other words, incomes and expenditures are calculated over the assumed ship's lifetime and the final sum must be positive for the investment to be profitable at the assumed discount rate. In case of alternatives are being compared, the best is the one resulting largest sum:

$$
N P V=\sum_{y=1}^{t} \frac{F_{y}}{(1+i)^{y}}-C A P E X
$$

Where $y$ is time of cash flow, $t$ is total time of project, $i$ is discount rate and $F$ is net cash flow, given by the difference between incomes and OPEX.

\section{Optimisation}

The objective function of the optimisation is to maximise the NPV, which is dependent on the synthesis, design and operation of the propulsion system. The synthesis concerns the number of propellers $\left(Z_{p}\right)$, which is the same of engines, and the usage or not of a re-liquefaction plant. The design concerns the propeller geometry, namely diameter $(D)$, pitch ratio $(P / D)$, blade-area ratio $\left(A_{E} / A_{O}\right)$ and number of blades $(Z)$, as well as the engine designation, namely identification (ID) and number of cylinders $\left(Z_{c}\right)$. The operation of the propulsion, in turn, concerns the service speeds during the voyage ( $V_{r w, a}, V_{r w, b}$ and $V_{r w, c}$ ) and the fuel profile (FP) to be adopted.

In order to find the best operational profile, four fuel profiles were defined as follows:

$\mathrm{FP}_{\mathrm{a}}$ - Burning MGO where is necessary, otherwise HFO, such that all BOG is re-liquefied.

$\mathrm{FP}_{\mathrm{b}}$ - Burning BOG where is necessary, otherwise HFO, such that only remaining BOG is reliquefied.

$\mathrm{FP}_{\mathrm{C}}$ - Burning BOG in laden, HFO in ballast and MGO where is necessary, such that only remaining BOG is re-liquefied.

$\mathrm{FP}_{\mathrm{d}}$ - Burning only BOG during the entire voyage, such that there is no re-liquefaction plant and remaining BOG is burnt in a GCU.

Table 1 presents the variables for the three levels of optimisation and sorts each one in continuous or discrete, as well as addresses their limiting values. It is worth to notice that six variables are continuous and five are discrete, as well as engine holds only discrete variables unlike both propeller and operation, which additionally keep continuous variables. Furthermore, some constraints currently under study will be also considered in subsequent works. 
Figure 9 illustrates the basic flow diagram of the proposed optimisation procedure. As shown, the procedure starts by estimating eight independent variables about propeller geometry, number of propellers and service speeds. Then computations in still water followed by computations in the selected weather are accomplished to reach the SMCR brake power and engine speed. Therewith, it is possible to determine which engines match the propeller and consecutively the NPV is calculated for every enginepropeller matching and fuel profile. By executing a simple search the other three dependent variables, namely combination of engine and fuel profile, which maximise the NPV, are found considering the independent variables as steady ones. Thus, a new estimate about independent variables is taken and the procedure is performed repeatedly until the convergence is reached.

Optimisation problems that arise in energy systems design often have several features that hinder the use of many optimisation techniques. These optimisation problems have non-continuous mixed variable definition domains, are heavily constrained, are multimodal (have many local optima) and, foremost, the functions used to define the engineering optimisation problem are often computationally intensive. In this case, it is preferred to utilise some evolutionary and stochastic methods as Genetic Algorithms, Differential Evolution, Particle Swarm and Simulated Annealing for instance. In this sense, a study about optimisation based on evolutionary and social metaphors applied in energy systems was carried out in Dimopoulos and Frangopoulos (2008c). Since the present study is in progress, a decision about the optimisation method to be applied has still not been made.

\section{CONCLUSION}

In this paper, a model to optimise the selection of LNG carriers’ propulsion system towards synthesis, design and operation, as well as the needed models, has been presented. The proposed procedure was developed based on a particular study case of a ship that has to accomplish three different service speeds, instead of only one as usually happens. As could be seen, six continuous and five discrete variables, including engine, propeller and operational ones, should be optimised to maximise the net present value of the project. However, the optimisation algorithm is responsible to optimise only eight independent variables whilst the rest are dependent ones and thereby they are optimised by simple search. Finally, it is suggested that this work may assist marine engineers and ship-owners to design and outline the operation of liquefied natural gas carriers.

Table 1. Optimisation variables and their limits.

\begin{tabular}{cccccccccc}
\hline & Propeller Variables & & Engine Variables & \multicolumn{3}{c}{ Operational Variables } \\
\hline Continuous & Limits & Discrete & Limits & Discrete & Limits & Continuous & Limits & Discrete & Limits \\
\hline$D[\mathrm{~m}]$ & $6.0-8.5$ & $Z[-]$ & $2-7$ & ID [-] & $1-16$ & $V_{r w, a}[\mathrm{kts}]$ & $10-12$ & FP & $1-4$ \\
$P / D[-]$ & $0.5-1.4$ & $Z_{p}[-]$ & $1-2$ & $Z_{c}[-]$ & $5-12$ & $V_{r w, b}[\mathrm{kts}]$ & $12-16$ & & \\
$A_{E} / A_{O}[-]$ & $0.30-1.05$ & & & & & $V_{r w, c}[\mathrm{kts}]$ & $16-19$ & \\
\hline
\end{tabular}

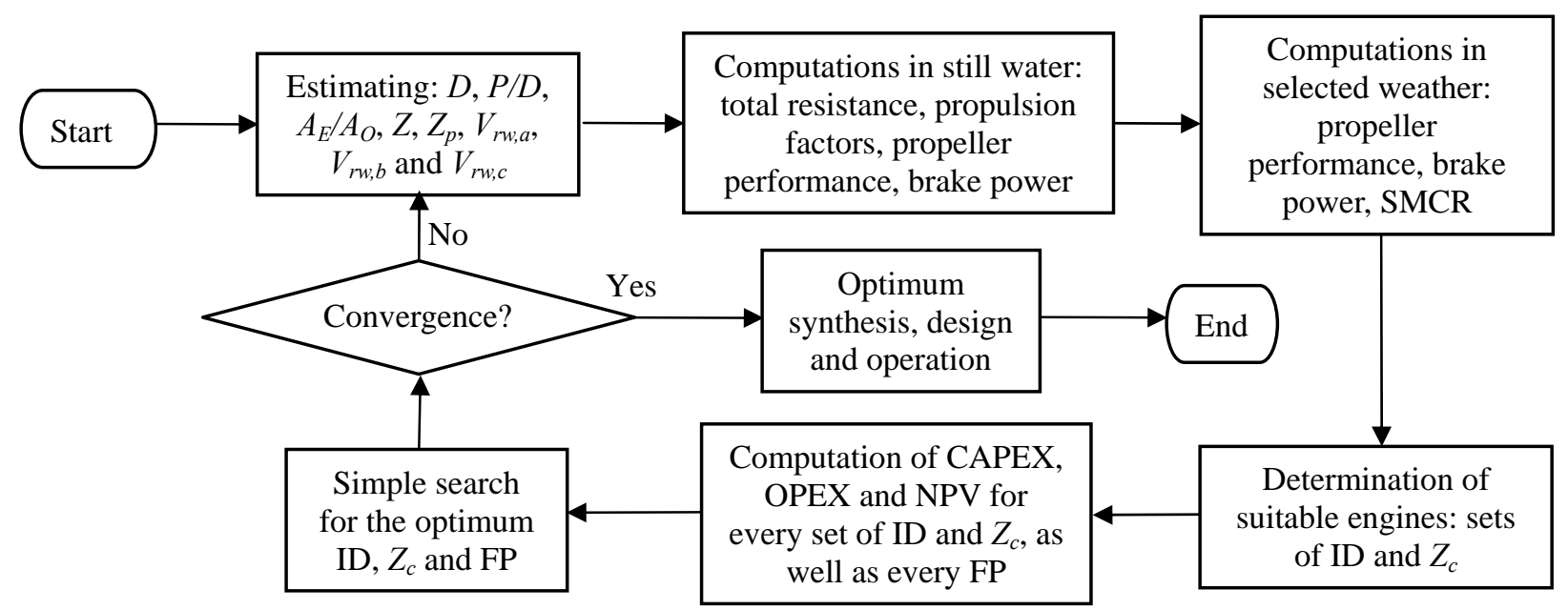

Figure 9. Basic flow diagram of the iterative optimisation procedure.

\section{REFERENCES}

Bulut, E., Duru, O., and Koak, G., 2015,
Rotational Priority Investigation in Fuzzy Analytic Hierarchy Process Design: an Empirical Study on the Marine Engine Selection Problem, Applied Mathematical Modelling, Vol. 39, pp. 913-923. 
Carlton, J. S., 2007, Marine Propellers and Propulsion, Butterworth-Heinemann, Oxford.

Conrad, O., Bechtel, B., Bock, M., Dietrich, H., Fischer, E., Gerlitz, L., Wehberg, J., Wichmann, V., and Boehner, J., 2015, System for Automated Geoscientific Analyses (SAGA), v. 2.1.4, Geoscientific Model Development, Vol. 8, pp. 19912007.

Dimopoulos, G. G., and Frangopoulos, C. A., 2008a, Synthesis, Design and Operation Optimization of the Marine Energy System for a Liquefied Natural Gas Carrier, International Journal of Thermodynamics, Vol. 11, No. 4, pp. 203-211.

Dimopoulos, G. G., and Frangopoulos, C. A., 2008b, A Dynamic Model for Liquefied Natural Gas Evaporation During Marine Transportation, International Journal of Thermodynamics, Vol. 11, No. 3, pp. 123-131.

Dimopoulos, G. G., and Frangopoulos, C. A., 2008c, Optimisation of Energy Systems based on Evolutionary and Social metaphors, Energy, Vol. 33, pp. 171-179.

Gilmore, R., Hatzigrigoris, S., Mavrakis, S., Spertos, A., and Vordonis, A., 2005, LNG Carrier Alternative Propulsion Systems, SNAME - Greek Section in 17 February.

Holtrop, J., and Mennen, G. G. J., 1982, An Approximate Power Prediction Method, International Shipbuilding Progress, Vol. 29, pp. 166-170.

Holtrop, J., 1984, A Statistical Re-analysis of Resistance and Propulsion Data, International Shipbuilding Progress, Vol. 31, pp. 272-276.

Kwon, Y. J., 2008, Speed Loss due to Added Resistance in Wind and Waves 3, Naval Architecture, Vol. 3, pp. 14-16.

Lamb, T., 2003, Ship Design and Construction, Sheridan Books, Chelsea.

Lu, R., Turan, O., Boulougouris, E., Banks, C., and Incecik, A., 2015, A Semi-Empirical Operational Performance Prediction Model for Voyage Optimization Towards Energy Efficient Shipping, Ocean Engineering, Vol. 110, pp. 18-28.

MAN Diesel \& Turbo, 2014, LNG Carriers with ME-GI Engine and High Pressure Gas Supply System, Denmark.

Miana, M., del Hoyo, R., Rodrigálvarez, V., Valdés, J. R., and Llorens, R., 2010, Calculation Models for Prediction of Liquefied Natural Gas (LNG) Ageing During Ship Transportation, Applied Energy, Vol. 87, pp. 1687-1700.

Michalski, J. P., 2007, A Method for Selection of Parameters of Ship Propulsion System Fitted with Compromise Screw Propeller, Polish Maritime Research, Vol. 14, pp. 3-9.

Mokhatab, S., Mak, J. Y., Valappil, J. V., and Wood, D. A., 2014, Hand Book of Liquefied Natural Gas, Gulf Professional, Oxford.

Oosterveld, M. W. C., and Ossannen, P. Van., 1975, Further Computer-Analysed Data of the Wageningen B-Screw Series, International
Shipbuilding Progress, Vol. 22, pp. 3-14.

Schneekluth, H., and Bertram, V., 1998, Ship

Design for Efficiency and Economy, ButterworthHeinemann, Oxford.

Watson, D. G. M., 2002, Practical Ship Design, Elsevier, Oxford.

Woodyard, D., 2009, Pounder's Marine Diesel Engines and Gas Turbines, Butterworth-Heinemann, Oxford.

Woud, H. K., and Stapersma, D., 2013, Design of Propulsion and Electric Power Generation Systems, IMarEST, London. 